\title{
The Effectiveness of Celebrity Involvement on Fans Behavior
}

\author{
Enxi Quan ${ }^{1, \dagger}$, Yao Xiao ${ }^{2, *}, \dagger$, Yiran Xu ${ }^{3, \dagger}$, Keren Zhao ${ }^{4, \dagger}$ \\ ${ }^{1}$ Guangzhou Huamei International School, Guangzhou, 510520, China \\ ${ }^{2}$ Our Lady of Good Counsel High School, Olney, 20832, USA \\ ${ }^{3}$ Dulwich International High School, Suzhou, 215021, China \\ ${ }^{4}$ NINGBO HANVOS KENT SCHOOL, The Barstow School Ningbo Campus, Ningbo, 315202, China \\ †These authors contributed equally \\ *Corresponding author: yx2865@nyu.edu
}

\begin{abstract}
Fan following is a spontaneous individual behavior, as one-way followers of stars' industrial chain. It realizes positive feedback on stars' performance strength and commercial value through continuous consumption behaviors. With the progress of media technology and the development of society, the identity attributes of stars and fans have undergone great changes. In the past, the cultural field of fans" "enclosure" has been broken. Under this condition, being as the loyal fan, they not only need to spend money for the stars, but also need to spend a lot of time on network data maintenance, so as to help stars maintain high popularity and good image. Therefore, this paper discussed the influence of celebrity participation on fans. The research mainly used literary analysis to support the evidence. This article found that all the people hold a rational attitude, even though the negative impact is still greater than the positive impact. The fan economy is often found to be a factor, but fortunately, the results are clear.
\end{abstract}

Keywords: Celebrity involvement, Idol, Fans' behavior, Fan culture, Society.

\section{INTRODUCTION}

\subsection{Background}

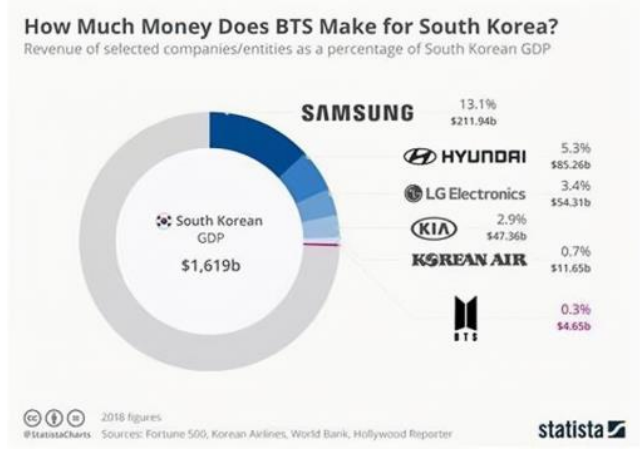

Figure 1 The contribution of BTS for South Korean GDP

Nowadays, the influence of celebrities is huge, and each of their actions is magnified and changes the behaviours of fans. In some circumstances, fans spend a lot of money on the celebrity; when a TV show invites a celebrity, fans who do not usually watch the show will be in front of the TV on time just for him or her. As a result, some industries or enterprises take advantage of this star effect. Through fan consumption, they have also made good gains. Take a famous international K-pop band BTS as a compelling example. In 2018 , they made 4.65 billion revenue through selling albums and concert tickets, which is about $0.3 \%$ of South Korean GDP (Figure 1).This substantial data not only improves their status, but also attracts more and more people to travel to South Korea. However, this kind of phenomenon sometimes tends to harm the social order. In China, many fans do irrational and counter-normal things for the benefit of their idols. The most common phenomenon is when a celebrity does something wrong. Most fans excuse and defend their celebrity instead of finding out the truth. Even worse, some fans will launch personal attacks or cyberbullying to someone who may hurt their idols. This behaviour often does not have a positive impact on celebrities, but rather makes others hate their fans and leads to a lower level of favour for celebrities. Recently in China, many celebrities and their fans not only wasted public resources but also destroyed the Internet and social order because of some bad or law-breaking behaviour. 
Therefore, to solve this negative phenomenon, the National International information office of the People's Republic of China deployed and carried out the "Chinglang" operations which is to purify the online environment including regulating undesirable fan culture. This operation not only makes a huge change in China's entertainment industry but also lets more and more people have a deeper understanding of the fan culture.

\subsection{Research Gap}

In the previous article, one object was separately studied, and two questions were studied, namely, "The Effectiveness of Celebrity endorsements" and "Status Quo, Problems, and Countermeasures of Fan culture". First of all, celebrity, celebrities frequently endorse products, brands, political candidates, or health campaigns. This analyzed celebrity endorsements in the context of for-profit and non-profit marketing. Findings revealed strong positive and negative effects when theoretically relevant moderators were included in the analysis [1]. In recent years, with the iteration and update of the Internet, fans occupy more and more media resources on the Internet and even in the real society, and have more and more powerful organizational power. Their performance in the network not only affects their idols but also makes the fan culture spread to other network cultures. As fans have different levels of education and self-cultivation, as individuals, they are easy to fall into the group carnival, get lost in the network, lose the ability to distinguish information and media literacy, resulting in the fans of collective network violence events emerging in an endless stream. Both abstracts describe the changes in celebrity endorsement and fans in recent years. Although the relationship between celebrities and fans has been explored before, due to the development of the fast Internet era, this post00s in China is in an irrational situation. But no one based on such a state to study, so this paper will research many domestic fans who will do some irrational things for the interests of fans, for example, the "milk pouring" incident of a talent show, the culture of fans, and the excessive "entertainment" of fans' economy, a lot of chaos and controversies about fans' support and the values of fans have emerged, drawing widespread concern in the society. Therefore, a gap appears; this study needs to fill the gap in this area of research. Such a situation is due to the fan culture theory. Fan economy is a brand-new star system different from the traditional star system. Fans participate in the operation of entertainers' public image utilizing crowd-funding and property. However in the actual operation, because there are too many loopholes are often used by criminals, resulting in a lot of economic losses.

On the one hand, the fans rely on Internet platforms and the organizers are anonymous. To trace their true identity requires the intervention of public security agencies and competent units. On the other hand, a considerable proportion of the victims are underage fans, who are reluctant to speak out after being cheated and do not know the channels for reporting and protecting their rights. Therefore, based on existing research, this paper can determine the next logical step of development, and research did questionnaire data analysis for this. They have a fan filter for their favorite people and have much imagination about them, but they will never know them in their whole life. Therefore, the star following is to fill some gaps in life without affecting a fan's life and to consume for stars within my ability.

\subsection{Structure of Paper}

Based on the known information, this paper assumes that the answer to the research question is the effectiveness of celebrity participation on fans' behavior. To verify the hypothesis, this paper will explore and verify the hypothesis in one main aspect and prove it by literature analysis. Based on fan culture theory, this paper mainly discusses the definition, function, and reasons of Fan culture from three aspects. According to information integration, it can be learned that the fan economy is a brand new star system different from the traditional star system. Fans participate in the operation activities of entertainers' public image utilizing crowd funding and property. However in the actual operation, because there are too many loopholes are often used by criminals, resulting in a lot of economic losses. On the one hand, the fans rely on Internet platforms and the organizers are anonymous. To trace their true identity requires the intervention of public security agencies and competent units. On the other hand, a considerable proportion of the victims are underage fans, who are reluctant to speak out after being cheated and do not know the channels for reporting and protecting their rights. Thus, the fan community should be wary of the manipulation of capital. Under such a conclusion, research can give reasonable opinions or suggestions for the better development of the fan group. Because of this situation, the relevant departments should improve the relevant laws and regulations as soon as possible, provide specific punishment basis and regulations for the fraud that may exist in the fans' assistance, and provide the victim fans, especially the minor fans, with reporting and other rights protection channels and legal aid. Fans' groups and artists who take the initiative to open their accounts, clarify the flow of funds and the specific use of funds, pay taxes actively, and accept industrial and commercial supervision actively will be recognized by issuing industry honors and awards and other measures, forming a good positive demonstration and leading role. The structure of this paper starts with an introduction and then makes a general direction as well as literary analysis, discussion, and final results 


\section{CELEBRITY}

\subsection{Definitions}

Celebrity used to refer to a famous woman in the communication field. Now refers to a person who has a certain influence in a certain field. Including famous actors, singers, artists, and athletes. In January 2018, at the regular public meeting of the state power administration, the director of the publicity department proposed that there should be standards for inviting guests from radio and television. For example, actors with low moral character should not be used. Vulgar actors are not used. Actors with low ideological level should not be used. Actors with stains and gossip are not needed. In addition, the general administration requires tattoo artists, hip-hop culture, subculture, and funeral culture not to be used in the program. Therefore, celebrities who meet these conditions are real stars.

Fans refer to people who is infatuated with and worship a celebrity or a group who worship a star, artist, or thing. Most of them are young people with a fashionable mentality. The "star chasers" from the 1980s and 1990s to the advent of the network era have the characteristics of one-way dissemination of information, limited forms of communication, low age of members, single forms of worship, and so on.

\subsection{Development}

In 1988, beyond held a special concert in Beijing Capital Gymnasium. On June 16, 1991, Zhao Chuan held the first solo concert of Hong Kong and Taiwan singers in Beijing Capital Gymnasium, which caused a great sensation. Qi Qin held three consecutive mainland concerts in Beijing on December 7, 8, and 9, 1991, which is regarded as a classic in the history of concerts. At that time, thousands of fans sang in unison downstairs of his hotel, and the media exclaimed that there were star fans in China.

However, in today' s society, fans have gradually become a derogatory term. The harm of star worship is also well known. Some star followers worship idols blindly and go crazy, which is harmful to their individuals and society. Some fans take idols as their spiritual support and live in a fantasy world all day, resulting in psychological imbalance. Some fans chase and intercept the stars in the public field, or secretly follow the stars, seriously disturbing the privacy of the stars, resulting in public order chaos.

Since August this year, in addition to Zheng Shuang being severely punished for tax evasion, several popular stars have been exposed for their immorality and anomie, including top stream star Wu Yifan who has been boycotted by the industry for bad behaviors such as being arrested on suspicion of rape. Therefore, experts say that the artistic cultivation and moral quality of some traffic stars are far from reaching the basic level of a singer or actor, so it's important to strengthen artistic cultivation and adhere to the moral bottom line. He also said that both singers and actors should learn basic legal knowledge and reject the vice of pornography, gambling, and poison. The lack of morality of pop stars not only harms the whole industry but also has a bad impact on the fan groups dominated by young people. Some fan groups have distorted into "strange circles" full of unhealthy tendencies, abusing each other, spending a lot of money to protect celebrities, and even trying to raise funds to rescue idols suspected of rape.

\subsection{Celebrity Endorsement}

Social relationships can produce a system of trust that facilitates beneficial activity [2]. This system can be used to benefit individuals, connecting them to an influential and vital figure in their surroundings, which is defined by the social capital theory, which describes social capital as resources to create social relationships and achieve positive social outcomes [3-6]. The internet helps facilitate such acquisition through its ability to connect people from all age groups with different interests worldwide. Social media, in particular, allows people to follow celebrities and public figures by engaging with them directly. Individuals can use this platform to achieve many connections that are unavailable offline. Social media platforms have a considerable influence that makes the celebrities' message available to potentially millions of people. Many have started using celebrities to endorse a product on social media because they influence consumers' brand awareness and loyalty [7]. A celebrity endorser with a high number of followers was significantly associated with higher ratings on source credibility compared to a celebrity endorser with a low number of followers; consumers perceived the celebrity with a high number of followers as being more physically attractive, trustworthy, and competent [8].

\subsection{Social Identity Theory}

Social identity theory defines social identity as the part of an individual's self-concept deriving from knowledge of their membership in a social group, together with the emotional and value-related significance attached to that membership [9]. According to this theory, people tend to be motivated to achieve positive distinctiveness by identifying with individuals or groups that help to implore their self-concepts [8]. When one identifies socially with an individual or group, the psychological separation between the self and others disappears, resulting in the view of oneself as an interchangeable member of one's social group [10]. When one identifies highly with a celebrity, the illusion 
of interactivity is created, making it easier for the celebrity to exert a social influence on the fan [11].

\subsection{Social Comparison Theory}

Social comparison theory defines social comparison as people engaging in comparison with others to fulfil a need for evaluation without objective, non-social criteria [12]. There are three specific types of social comparison: upward (comparison with others who are perceived as better), downward (comparison with others who are perceived as less fortunate), and lateral comparison (comparison with others who are similar) [12-14]. Peers and celebrities are important referent targets for adolescents as they tend to look to social media figures as role models, and people are innately inclined to compare with similar others, and one's peers provide the most reliable and stable evaluations of themselves [12, 13, 15]. A study done on adolescents has shown that social comparison with friends on social media has been a significant antecedent of body image dissatisfaction, their drive to be thin or muscular: social comparison with celebrities on social media was only positively associated with females' body image dissatisfaction and their drive to be thin; the relationship between social comparison with celebrities and males' body image dissatisfaction and their drive to be muscular were non-significant; celebrity involvement was positively associated with males' body image dissatisfaction and their drive to be muscular [16]. The paper has suggested that comparing with peers on social media has a stronger relationship with body image dissatisfaction and their drive to be muscular/thin than for celebrities, for adolescents [16].

To sum up, according to the literature, it is obvious to see that social media has become an important channel for stars and fans to communicate in today's society. Stars interact with their fans in their way, deepening their connection with them and gaining a high degree of recognition and trust from their fans. For some teenagers, stars are more regarded as idols, because the idea is not yet mature, every behavior of the idol has a big impact on them. In addition, some people are willing to compare with stars, including body, appearance, etc. This comparison will, to some extent, make them change their lives and motivate them to improve themselves, but it will also create some ineffective anxiety.

\section{RESULTS}

In many people's stereotypes, fan following is a spontaneous individual behavior, which can be the exclusive memory of a person who enjoys himself or the collective memory of a small group of people who "enclosure the land and sprout the stars". They used to support their idos by purchasing large amonut of movie tickets, music tapes than they need. so the commercial value and professional skill of their favorite star can be better withdrawn. At the same time, the companies the stars belong to need to continuously produce excellent works and attractive cultural products to accumulate and maintain the growing relationship between fans and stars. With the progress of media technology and the development of society, the identity attributes of stars and fans have undergone great changes. With the advent of the Internet era, the traditional fandom culture has been broken, fans and their favorite stars have to face the opportunities and challenges together. Under the guidance of the capital platform, the fan effect is gradually transformed into quantifiable and evaluable big data and large flow. The number of groups, activeness, forwarding rate and number of comments can all become important indicators and development indicators to evaluate the commercial value of stars. In this way, stars can get more shots and performances, get more commercial endorsements, and show stronger brand value. However, fan culture precisely lies in the sense of participation and companionship. Through the emotional strategies of companionship, empathy, and protection formed by interaction with artists, fan culture seeks to construct a new social relationship among teenagers in the new media era represented by the Internet. Only by fully understanding the changes in the deep social structure can get to the root of shaping the values of the current fan group, and only on this basis can correctly guide the values of the fan group have realistic feasibility. Therefore, the questionnaire research shows that the public still has different opinions on the fan circle, and most people believe that the fan group should establish and guide the correct values.

From our research, our members found out both those who follow celebrities and those who do not follow celebrities think that they should keep a rational attitude towards their idols. Although a few people will find it difficult to understand the fan group, most people think that everyone has their favorite things, just respect, and understanding, not to be too addictive is also very important. Moreover, idols have great power over fans. Many people have changed their lives or personalities because of idols. It is more because they regard idols as role models to inspire themselves to become better people and shorten the distance between themselves and idols. Nowadays, to satisfy themselves, many fans will do some immoral and legal things, and their idols do not stop them, which leads to the increasingly serious disorder of the fan group, which has greatly affected the order of social media. There is also a large group of people in the fan community who support positivity. Both celebrities and fans are responsible for fan culture. During this period, many stars are constantly improving their popularity, but they use their popularity to do something beyond morality, such as the Wu Yifan incident, which has caused a very bad influence. As a result, fans increasingly expect celebrities to spread correct values and morality and make contributions to the positive 
development of society. In recent years, stars cannot live without their fans. Their debut and image require the management of fans. Due to competing resources, fans can insult each other and spend a lot of money. Therefore, the public expects celebrities to guide their fans to follow stars rationally, have the courage to stop such bad behavior, and take the lead in obeying the law. While enjoying being famous, celebrities also need to stay awake and help each other grow with their fans. In addition, the government now attaches great importance to the management and restriction of celebrities' behaviors. If celebrities have ever committed such acts of bad or illegal social impact, they are forbidden to appear in front of cameras or participate in any variety shows. Therefore, people believe that under the reasonable rectification of the Chinese government, more and more improper behaviors in the fan group will be greatly reduced, and the behaviors of some celebrities will also be regulated, which will not only greatly improve the quality of our fans, but also greatly improve the online society.

\section{DISCUSSION}

According to the result, it is obvious to see that the impact of idol behavior on fans is enormous. When celebrities do have a positive impact, it will give fans greatly the power of life and mental satisfaction, but if the celebrity something against themselves or industry standards and the laws and regulations, fans not only themselves will produce some negative emotions, but also will have a serious impact on the public resources as well as some of them even take a long time to adjust the state of mind. This kind of behavior is mostly caused by role models $[2,7,12]$. Fans regard their idols as their life goals. They think that their idols are already excellent and they need to work hard enough to shorten the distance between them and their idols. To achieve this, they will achieve a kind of spiritual support given by their idols through various ways, such as watching their idols' stage, variety shows, and other activities to get pleasure. Therefore, as idols or celebrities, in order to ensure their continuous output of good works, they also need to pay attention to their words and deeds to the public. What is more, the most important thing for idols is to learn to be grateful. They should realize that what they have achieved is not only their efforts but also the support of their fans and people around them. They should bear this in mind before doing anything. For fans, it is important to remember that this is their own lives before following the stars. They must think carefully, and don't regret it because of a momentary impulse. In addition, fans should develop the relationship with the idols in a positive direction, pay more attention to their works, and do not interfere too much in their lives in the name of fans, since everyone has their privacy.

\section{CONCLUSION}

In conclusion, this review combines existing articles on whether celebrity participation affects fans' behavior. According to the analysis, the behaviors of stars have both positive and negative effects on fans. The positive effects are that fans can have positive development in their life by following the example of stars. The negative effect is that some irrational behaviors of fans cause harm to themselves and society. Based on the analysis, the film also puts forward some suggestions on the behavior of stars and fans: stars should reasonably regulate their behavior, and fans should follow stars rationally, etc. Besides, this study is a subjective judgment of the analysis, and more investigations and evaluations are needed in the future.

\section{REFERENCES}

[1] Knoll, J., Matthes, J. (2017) The effectiveness of celebrity endorsements: a meta-analysis. Journal of the Academy of Marketing Sience, 45.1: 55-75

[2] Coleman, J.S. (1988) Social capital in the creation of human capital. American journal of sociology, 94: S95-S120.

[3] Bourdieu, P. (2018) The forms of capital. Rougledge, London.

[4] Burt, R.S. (2003) The social structure of competition. Networks in the knowledge economy, 13: 57-91.

[5] Putnam, R.D. (2000) Bowling alone: The collapse and revival of American community. Simon and schuster, New York City.

[6] Lin, N. (2002) Social capital: A theory of social structure and action Vol. 19. Cambridge university press, Cambridge.

[7] Miller, F.M., Laczniak, G.R. (2011) The ethics of celebrity-athlete endorsement: What happens when a star steps out of bounds?. Journal of Advertising Research, 51.3: 499-510.

[8] Jin, S.A.A., Phua, J. (2014) Following celebrities' tweets about brands: The impact of twitter-based electronic word-of-mouth on consumers' source credibility perception, buying intention, and social identification with celebrities. Journal of advertising, 43.2: 181-195.

[9] Tajfel, H., Turner, J.C., Austin, W.G., Worchel, S. (1979) An integrative theory of intergroup conflict. Organizational identity: A reader, 56.65: 9780203505984-16.

[10] Aron, A., Aron, E.N., Smollan, D. (1992) Inclusion of other in the self scale and the structure of 
interpersonal closeness. Journal of personality and social psychology, 63.4: 596.

[11] Rubin, A.M., Perse, E.M., Powell, R.A. (1985) Loneliness, parasocial interaction, and local television news viewing. Human communication research, 12.2: 155-180.

[12] Festinger, L. (1954) A theory of social comparison processes. Human Relations, 7.2: 117-140.

[13] Taylor, S.E., Lobel, M. (1989) Social comparison activity under threat: downward evaluation and upward contacts. Psychological review, 96.4: 569.

[14] Morrison, T.G., Kalin, R., Morrison, M.A. (2004) BODY-IMAGE EVALUATION AND BODYIMAGE AMONG ADOLESCENTS: A TEST OF
SOCIOCULTURAL AND SOCIAL COMPARISON THEORIES, Adolescence, 39.155.

[15] Giles, D.C., Maltby, J. (2004) The role of media figures in adolescent development: Relations between autonomy, attachment, and interest in celebrities. Personality and individual differences, 36.4: 813-822.

[16] Ho, S.S., Lee, E.W., Liao, Y. (2016) Social network sites, friends, and celebrities: The roles of social comparison and celebrity involvement in adolescents' body image dissatisfaction. Social Media+ Society, 2.3: 2056305116664216. 